\title{
Molecular screening of wheat entries for resistance to the toxins Ptr ToxA and Ptr ToxB from the tan spot pathogen Pyrenophora tritici-repentis
}

\author{
A.M. Kokhmetova ${ }^{1 *}$, S. Ali $^{2}$, M.N. Atishova ${ }^{1}$ \\ ${ }^{1}$ Institute of Plant Biology and Biotechnology, Almaty, Kazakhstan \\ ${ }^{2}$ South Dakota State University, Brookings, USA
}

DOI 10.18699/ICG-PlantGen2019-20

(c) Autors, 2019

*e-mail:gen_kalma@mail.ru

\begin{abstract}
Tan spot caused by Pyrenophora tritici-repentis is a serious wheat disease. The aim of this study was the identification of genotypes resistant to $P$. tritici-repentis race 1 and 5 and their host-selective effectors Ptr ToxA and Ptr ToxB. 41 wheat accessions where characterized using molecular markers, diagnostic for the Tsn1 and Tsc2 genes. The accuracy of the marker XBE444541 was $92.11 \%$ with race 5 and $97.37 \%$ with Ptr ToxB. Genotyping results demonstrate the reliability of the marker $X f c p 623$ for identifying genotypes insensitive to Ptr ToxA. $78 \%$ of genotypes exhibited resistance to both race 1 and race 5 and to the toxins Ptr ToxA and ToxB. The results are of interest for efficient breeding based on the elimination of the genotypes with the dominant alleles Tsn1 and Tsc2, sensitive to Ptr ToxA and ToxB.
\end{abstract}

Key words: wheat; Pyrenophora tritici-repentis; tan spot; Tsn 1; Tsc2; ToxA; ToxB.

\section{Introduction}

Pyrenophora tritici-repentis (Died.) Drechsler is the causal agent of tan spot, a major foliar blight disease in wheatgrowing areas throughout the world (Duveiller et al., 1998). Yield losses can rise beyond $50 \%$. P. tritici-repentis produces multiple Host Selective Effectors (toxins) acting as pathogenicity/virulence factors. Five toxins (Ptr ToxA, B, C, and two toxins collectively known as Ptr ToxD) have been identified. The Tsn1-Ptr ToxA, Tsc2-Ptr ToxB, and Tsc1-Ptr ToxC interactions have all been shown to play significant roles in the development of tan spot in wheat (Faris et al., 2013). Molecular markers accelerated the characterization of wheat cultivars with superior resistance by rapid identification of related genes. Breeding for resistance to tan spot could be enhanced if additional resistance sources effective against multiple Ptr races were identified. The aim of this study was the identification of wheat genotypes resistant to P. triticirepentis race 1 and race 5 and their host-selective effectors (toxins) Ptr ToxA and Ptr ToxB.

\section{Materials and methods}

A common wheat collection of 41 accessions was assayed in the greenhouse at the two-leaf seedlings stage. The plants were rated for disease, using the scale based on lesion type (Lamari, Bernier, 1989). Toxin infiltration using purified toxins Ptr ToxA and Ptr ToxB was performed at the stage of two leaves (Xu et al., 2004). DNA was extracted from leaf powder following the protocol described by Riede and Anderson (1996). The wheat accessions were characterized using the molecular markers $X f c p 623$ and XBE4444541 diagnostic for the $T s n 1$ and $T s c 2$ genes conferring the sensitivity to fungal toxins. PCR was performed according to literature conditions (Zhang et al., 2009; Abeysekara et al., 2010). The amplification products were visualized by electrophoresis in $2 \%$ agarose gels in the TBE buffer with subsequent staining with ethidium bromide and the use of the GelDoc BIO-PRINT MEGA for documentation of allele types in cultivars. Wheat entries 6B662 and Glenlea served as positive and negative controls, respectively.

\section{Results and discussion}

Genotyping of wheat accessions using molecular markers was aimed at identifying the carriers of genes conferring sensitivity and resistance to HST Ptr ToxA and ToxB. The frequency of entries resistant to race 1 and race 5 in the wheat collection amounted to $78.95 \%$. Of greatest interest are 8 cultivars: Kokbiday, 428g / MK-122A, Lutescens 90, Lazzat, Omskaya 28, Omskaya 36, SOMO / SORA / ACTS5, BR14 / CEP847-1 and BR14 / CEP847-2, which showed high resistance both to the two races (race 1 and race 5), and to the two toxins (Ptr ToxA and ToxB), and also confirmed insensitivity to the HST during molecular screening. A moderate degree of resistance to the $P$. tritici-repentis races and toxins was observed in 21 wheat entries.

As an example, the results of the PCR amplification products, when the $X f c p 623$ primers were tested on 19 wheat genotypes, are shown in Figure 1. The molecular marker Xfcp623 linked the recessive $t s n 1$ allele conferring insensitivity to Ptr ToxA. As shown in Figure 1, 12 out of 19 entries each had a polymorphic band identical to $X f c p 623$. The marker $X f c p 623$ amplified a 380-bp fragment associated with the Tsn1 gene sensitive to Ptr ToxA in 8 wheat entries.

In summary, the results of genotyping presented in this study indicate that the marker Xfcp623 had a null allele associated with insensitivity to the toxin in 30 out of 41 wheat accessions. The presence / absence of the marker Xfcp623 absolutely (100\%) coincided with the sensitivity / resistance to race 1 and Ptr ToxA. It demonstrates the reliability of $X f c p 623$ 


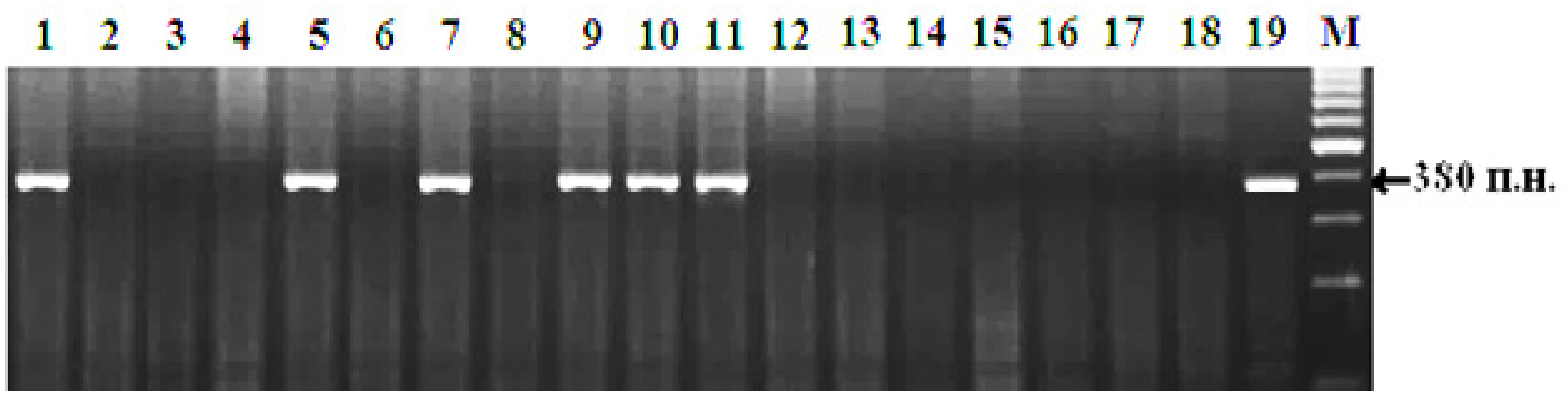

Figure 1. DNA amplification products of wheat accessions using primers to the diagnostic marker Xfcp623 linked to the Tsn 1 gene, controlling sensitivity to Ptr ToxA. Resolved in $2 \%$ agarose gel.

Note: 1, 428/Umanka-17; 2, 428g/MK-122A; 3, Kokbiday; 4, Lazzat; 5, 428/Umanka-18; 6, Omskaya 28; 7, KR11-20; 8, Omskaya 36; 9, JAS58/JAS55//ALD/3/MRNG/4/ ALD; 10, Koksu; 11, ZM23524; 12, SOMO/SORO/ACTS5; 13, BR14/CEP847; 14, Astana; 15, Kazakhstanskaya 25; 16, Kazakhstanskaya Rannespelaya; 17, Keremet; 18, Salamouni; 19, Glenlea, M, molecular weight marker (Gene-RulerTM; 100 bp DNA Ladder (Ferments, Lihuania)).

as a diagnostic marker for identifying wheat genotypes with resistance to the fungus and insensitivity to Ptr ToxA.

The marker XBE444541 amplified a 340-bp fragment associated with the $T s c 2$ gene, which is sensitive to Ptr ToxB in 8 wheat samples. Five of these entries were also sensitive to race 5. This marker amplified a 505-bp fragment associated with insensitivity to Ptr ToxB in 30 wheat entries. The coincidence of the marker XBE444541 was $92.11 \%$ with resistance to race 5 and $97.37 \%$ with resistance to Ptr ToxB.

The study of the reaction of wheat germplasm to fungal inoculation and toxin infiltration showed that 30 genotypes (78\%) exhibited resistance to both race 1 and race 5, and insensitivity to Ptr ToxA and ToxB. Sensitivity to Ptr ToxB is not always correlated with susceptibility to race 5 and depends on the host's genetic background of the wheat genotype, i. e. on the particular wheat genotype.

Despite the fact that tan spot is one of the most important diseases of wheat, there are still insufficient publications on resistance to the prevailing $P$. tritici-repentis races of wheat varieties cultivated in Kazakhstan. Our study is one of the first in this region, including comprehensive screening using races and purified toxins, as well as molecular analysis for the presence of target disease resistance genes. Recently, studies aimed at assessing the resistance of wheat germplasm to tan spot have been conducted (Singh et al., 2016; Kokhmetova et al., 2017, 2018). Many studies have shown statistically significant relationships between sensitivity to NE and susceptibility to $P$. tritici-repentis (Friesen, Faris, 2004; Abeysekara et al., 2010). The problem of identifying sources of resistance to P. tritici-repentis in our study was solved by using isolates of races and the toxins Ptr ToxA and Ptr ToxB. Our data are consistent with the results of a number of studies, where it has been shown that sensitivity to NE does not always determine sensitivity to $P$. tritici-repentis, and the involvement of interactions in the development of the disease depends on the host's genetic background (Kariyawasam et al., 2016). The results of the study are of interest for increasing the efficiency of breeding based on the elimination of the genotypes with the dominant alleles $T s n 1$ and $T s c 2$ sensitive to the toxins Ptr
ToxA and ToxB. The genotypes will be used in breeding for resistance to tan spot.

\section{Conclusions}

The results of genotyping and screening using necrotrophic effectors are of interest for increasing the efficiency of breeding on the basis of elimination of the carriers of the dominant alleles $T s n 1$ and $T s c 2$ controlling sensitivity to the toxins Ptr ToxA and ToxB from breeding material. All these data allow assuming that the carriers of the $t s n 1$ and $t s c 2$ genes conferring insensitivity to Ptr ToxA and ToxB can be used in breeding programs for the pyramiding of disease resistance genes. International collaboration with the CIMMYT is of great importance for successful breeding for tan spot resistance. Sources from different countries with broad-spectrum resistance to tan spot may contribute to resistance observed in our study and can be utilized to develop cultivars with durable resistance to tan spot. Our study generally creates opportunities for transferring the breeding process in Kazakhstan to a new scientific level due to the application of molecular and pathological methods. The results are used in wheat breeding programs for tan spot resistance with the Marker Assisted Selection.

\section{References}

Abeysekara N.S., Friesen T.L., Liu Z., McClean P.E., Faris J.D. Marker development and saturation mapping of the tan spot Ptr ToxB sensitivity locus Tsc2 in hexaploid wheat. Plant Gen. 2010;3:179-189. DOI 10.3835/plantgenome2010.07.0017.

Duveiller E., Dubin H.J., Reeves J., McNab A. Helminthosporium Blights of Wheat: Spot Blotch and Tan Spot. CIMMYT, 1998. El Batán, Mexico.

Faris J.D., Liu Z., Xu S.S. Genetics of tan spot resistance in wheat. Theor. Appl. Genet. 2013;126(9):2197-2217. DOI 10.1007/s00122013-2157-y.

Friesen T.L., Faris J.D. Molecular mapping of resistance to Pyrenophora tritici-repentis race 5 and sensitivity to $P \operatorname{tr} T o x B$ in wheat. Theor. Appl. Genet. 2004;109:464-471. DOI 10.1007/s00122-004-1678-9.

Kariyawasam G.K., Carter A.H., Rasmussen J.B., Faris J.D., Xu S.S., Mergoum M., Liu Z. Genetic relationships between race-nonspecific and race specific interactions in the wheat-Pyrenophora tritici-re- 
pentis pathosystem. Theor. Appl. Genet. 2016;129:897-908. DOI org/10.1007/s00122-016-2670-x.

Kokhmetova A., Kremneva O., Volkova G., Atishova M., Sapakhova Z. Evaluation of wheat cultivars growing in Kazakhstan and Russia for resistance to tan spot. J. Plant Pathol. 2017;99(1):161-167. DOI 10.4454/jpp.v99i1.3812.

Kokhmetova A.M., Ali S., Sapakhova Z., Atishova M.N. Identifcation of genotypes - carriers of resistance to tan spot Ptr ToxA and Ptr ToxB of Pyrenophora tritici-repentis in common wheat collection. Vavilov J. Genet. Breed. 2018;22(8):978-986. DOI 10.18699/ VJ18.440 (In Russian).

Lamari L., Bernier C.C. Evalution of wheat lines and cultivars to tan spot [Pyrenophora tritici-repentis] based on lesion type. Can. J. Plant Sci. 1989;11(1):49-56.

Riede C.R., Anderson J.A. Linkage of RFLP markers to an aluminum tolerance gene in wheat. Crop Sci. 1996;36(4):905-909.
Singh P.K., Crossa J., Duveiller E., Singh R., Djurle A. Association mapping for resistance to tan spot induced by $P$. tritici-repentis race 1 in a CIMMYTs historical bread wheat set. Euphytica. 2016; 207(3):515-525. DOI 10.1007/s10681-015-1528-7.

Xu S.S., Friesen T.L., Mujeeb-Kazi A. Seedling resistance to tan spot and Stagonospora nodorum blotch in synthetic hexaploid wheats. Crop Sci. 2004:44:2238-2245.

Zhang Z., Friesen T.L., Simons K.J., Xu S.S., Faris J.D. Development, identification, and validation of markers for marker assisted selection against the Stagonospora nodorum toxin sensitivity genes Tsn1 and Snn2 in wheat. Mol. Breed. 2009; 23:35-49. DOI 10.1007/ s11032-008-9211-5.

Acknowledgements. The work is supported by the granting project No. AP05132540 of the Ministry of Education and Science of the Republic of Kazakhstan.

Conflict of interest. The authors declare no conflict of interest. 